\title{
Chemical vapor deposition of superconducting
}

\section{FeTe $_{1-\mathrm{x}} \mathrm{Se}_{\mathrm{x}}$ nanosheets}

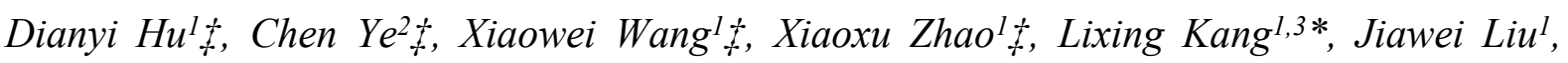
Ruihuan Duan ${ }^{1}$, Xun Cao ${ }^{1}$, Yanchao He ${ }^{1}$, Junxiong Hü ${ }^{4}$, Shengyao Li $^{2}$, Qingsheng Zeng ${ }^{1}, Y a$ Deng ${ }^{1}$, Peng-Fei Yin ${ }^{5}$, Ariando Ariando ${ }^{4}$, Yizhong Huang ${ }^{1}$, Hua Zhang ${ }^{5,6,7}$, Xiao Renshaw Wang $^{2,8 *}$, Zheng $\operatorname{Liu}^{1,8,9 *}$

${ }^{1}$ School of Materials Science and Engineering, Nanyang Technological University, Singapore, 639798, Singapore

${ }^{2}$ School of Physical and Mathematical Sciences, Nanyang Technological University, Singapore, 637371, Singapore

${ }^{3}$ Division of Advanced Materials, Suzhou Institute of Nano-Tech and Nano-Bionics, Chinese Academy of Sciences, Suzhou, 215123, China

${ }^{4}$ Department of Physics, National University of Singapore, 117551, Singapore

${ }^{5}$ Department of Chemistry, City University of Hong Kong, 83 Tat Chee Avenue, Kowloon, Hong Kong, China

${ }^{6}$ Hong Kong Branch of National Precious Metals Material Engineering Research Center (NPMM), City University of Hong Kong, Hong Kong, China 
${ }^{7}$ Shenzhen Research Institute, City University of Hong Kong, Shenzhen, 518057, China

${ }^{8}$ School of Electrical and Electronic Engineering, Nanyang Technological University, Singapore, 639798, Singapore

${ }^{9}$ CINTRA CNRS/NTU/THALES, UMI 3288, Research Techno Plaza, Singapore, 637553, Singapore

\$These authors contributed equally to this work. 

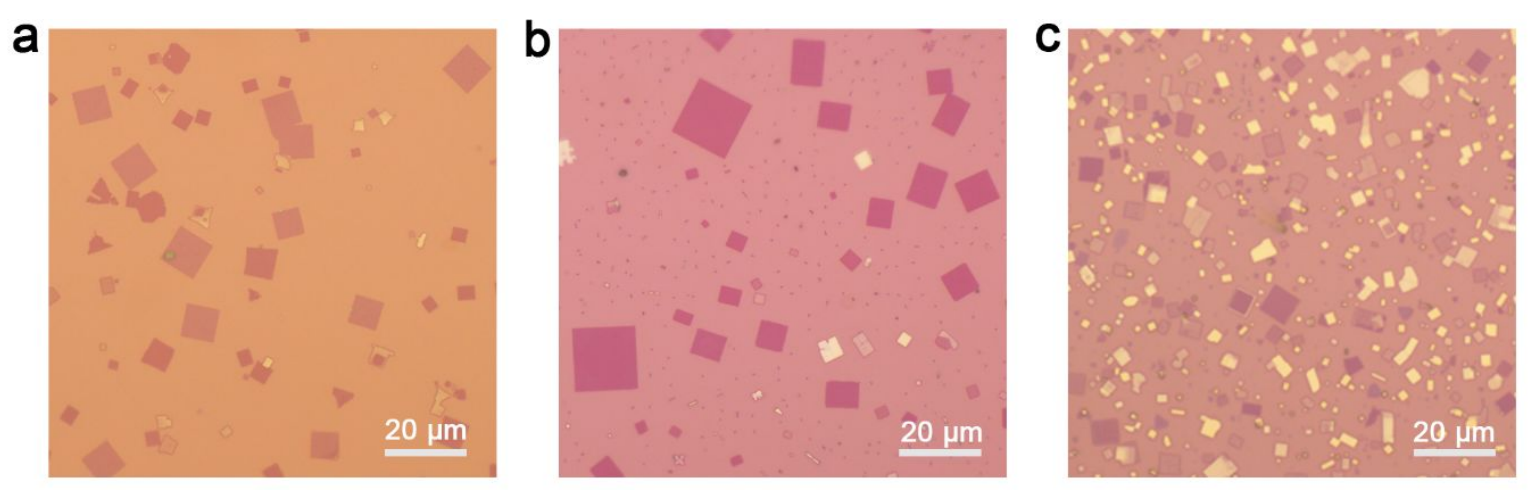

Figure S1. Optical microscopic images of $\mathrm{FeTe}_{1-\mathrm{x}} \mathrm{Se}_{\mathrm{x}}$ synthesized at reaction temperatures of (a) $500{ }^{\circ} \mathrm{C}$, (b) $520^{\circ} \mathrm{C}$ and (c) $540{ }^{\circ} \mathrm{C}$. 
a

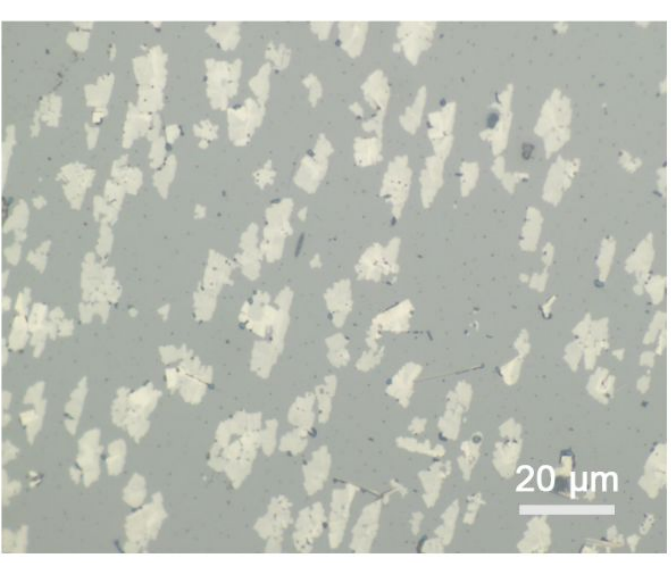

b

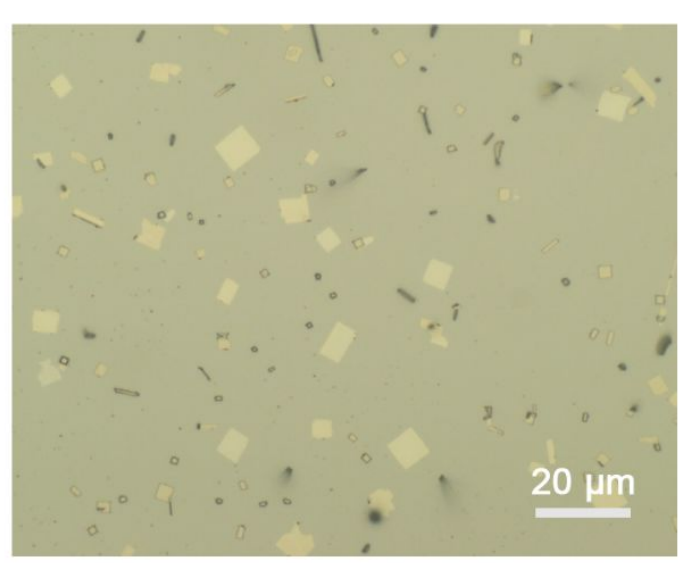

Figure S2. Optical microscopic images showing the morphologies of $\mathrm{FeTe}_{1-\mathrm{x}} \mathrm{Se}_{\mathrm{x}}$ prepared on different types of substrates, i.e., (a) STO(110) and (b) $\operatorname{Si}(100)$. 


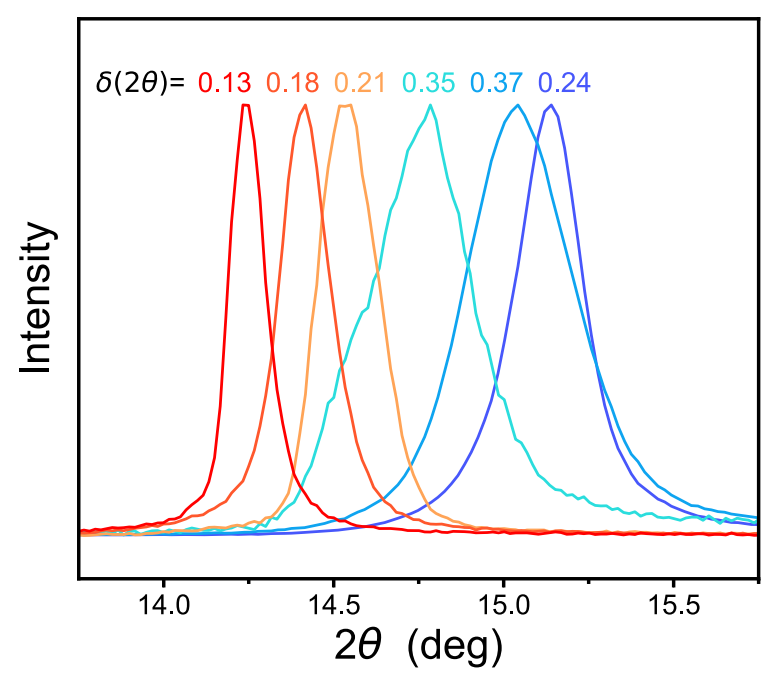

Figure S3. XRD patterns of $\mathrm{FeTe}_{1-\mathrm{x}} \mathrm{Se}_{\mathrm{x}}$ samples with different compositions. $\mathrm{x}=0,0.23,0.33$, 0.5, 0.67 and 0.74 from left to right. Their corresponding full widths at half maximum (FWHM), $\delta(2 \theta)$, are marked accordingly. 


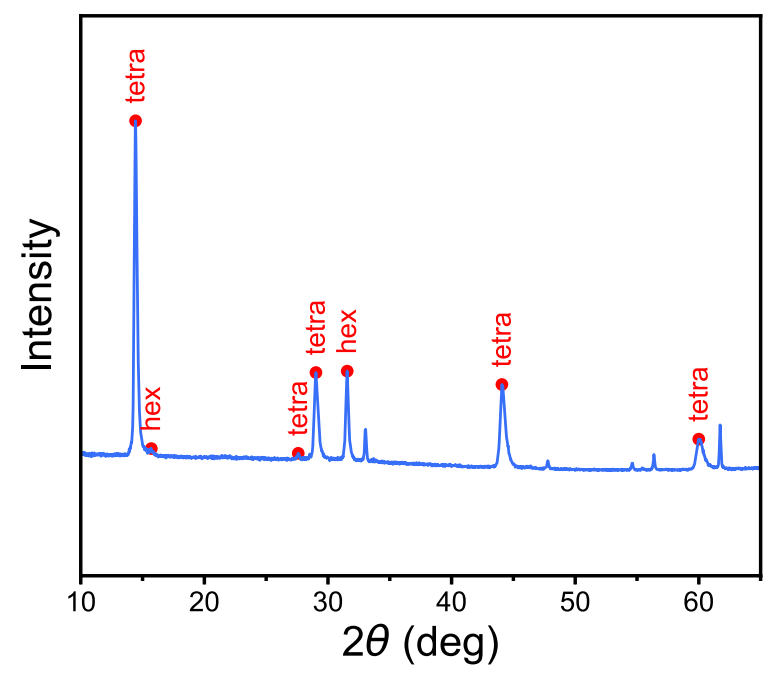

Figure S4. XRD pattern of $\mathrm{FeTe}_{1-\mathrm{x}} \mathrm{Se}_{\mathrm{x}}$ with the existence of both tetragonal and hexagonal phases, synthesized when the temperature of Te and Se is too high. 


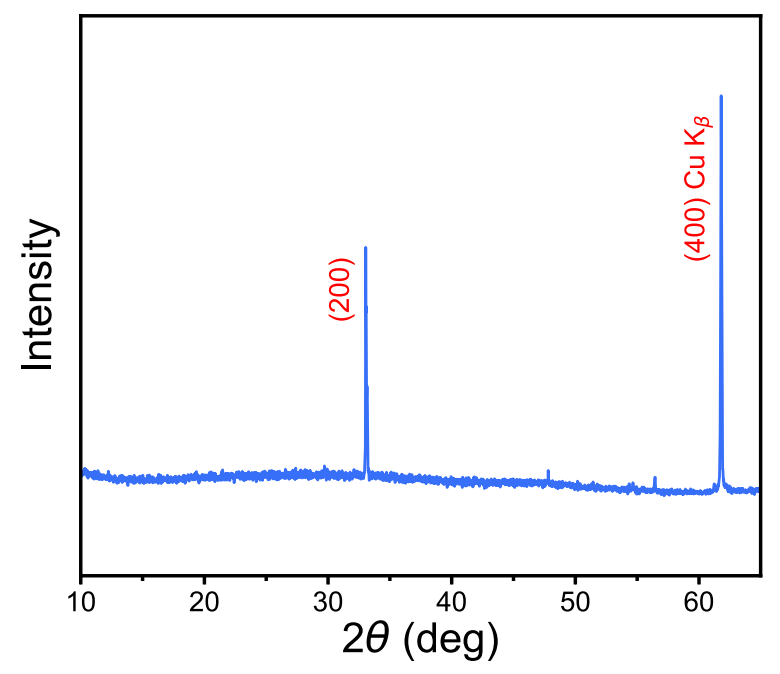

Figure S5. XRD pattern of the $\mathrm{SiO}_{2} / \mathrm{Si}$ substrate. 

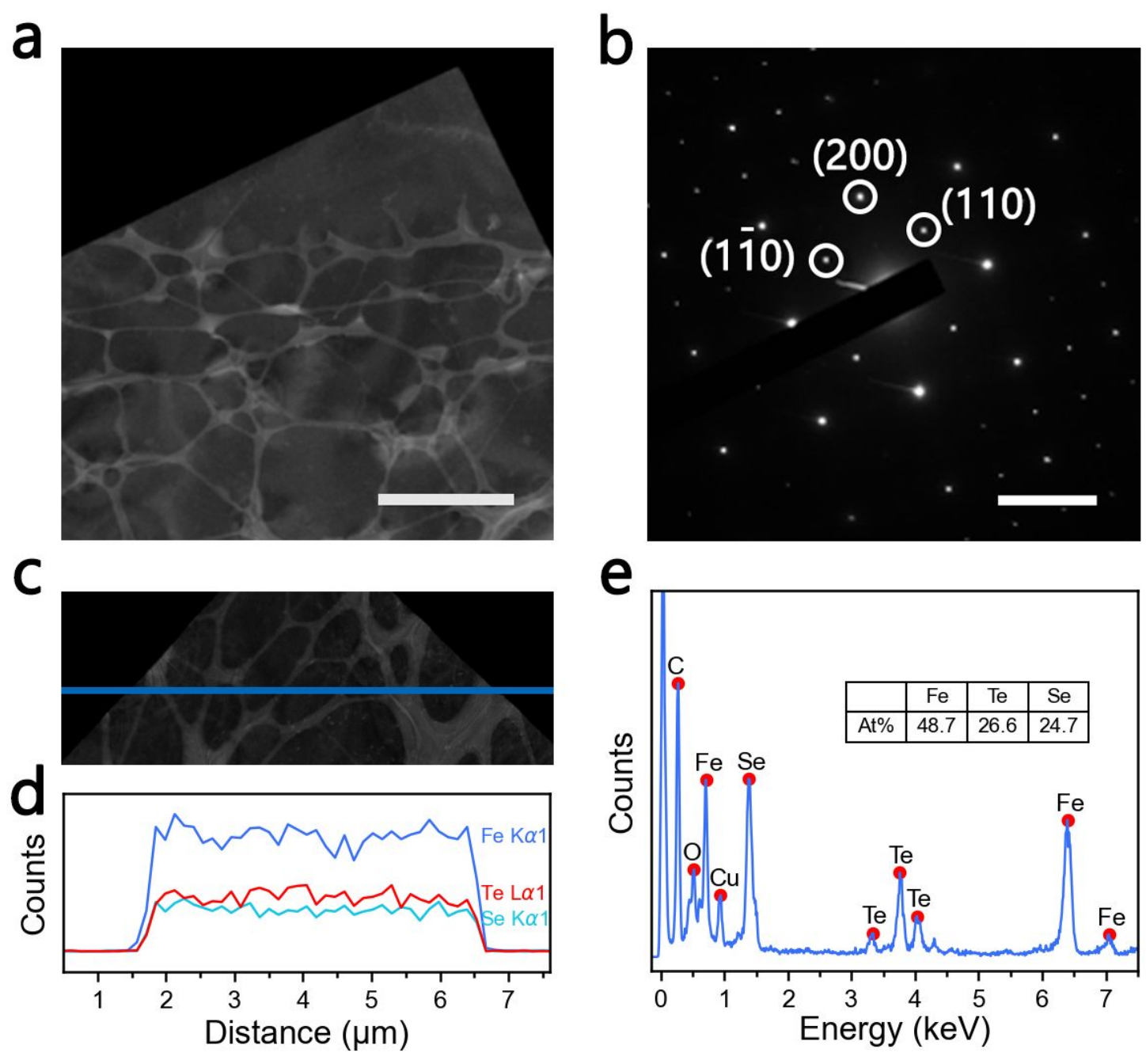

Figure S6. (a) STEM image of a typical $\mathrm{FeTe}_{1-\mathrm{x}} \mathrm{Se}_{\mathrm{x}}$ nanosheet on the Cu grid. (b) SAED pattern of a $\mathrm{FeTe}_{1-\mathrm{x}} \mathrm{Se}_{\mathrm{x}}$ nanosheet, showing its single-crystalline nature. (c) STEM image and (d) the corresponding EDS line scan result of Fe Ka1, Se K $\alpha 1$ and Te L $\alpha 1$ along the solid blue line marked in (c). (e) EDS spectrum of the $\mathrm{FeTe}_{1-\mathrm{x}} \mathrm{Se}_{\mathrm{x}}$ flakes, showing the atomic ratio of $\mathrm{Fe} / \mathrm{Te} / \mathrm{Se}$ to be 48.7:26.6:24.7. Scale bars, (a) $2 \mu \mathrm{m}$; (b) $51 / \mathrm{nm}$. 

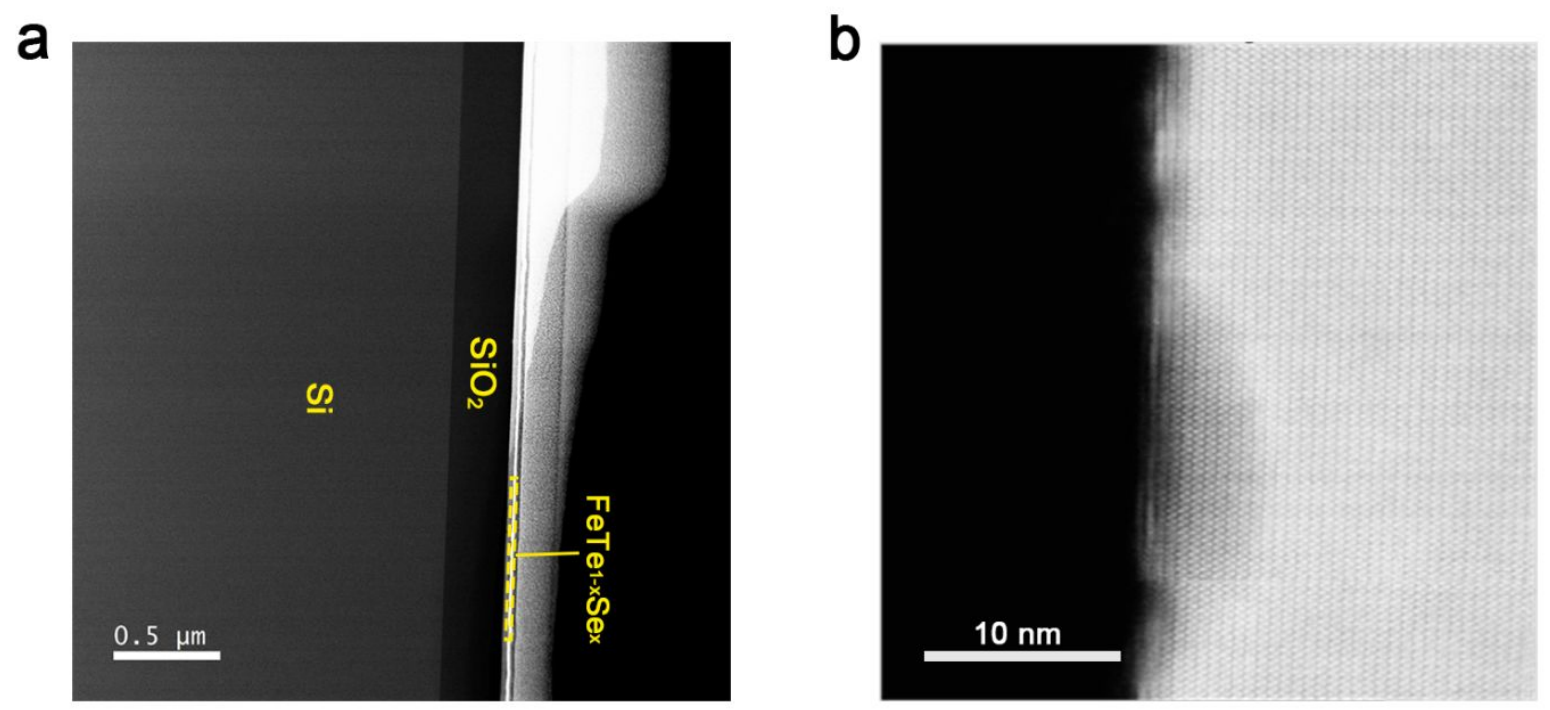

Figure S7. (a) Low and (b) high-magnification HAADF-STEM images of the cross-section of the $\mathrm{FeTe}_{1-\mathrm{x}} \mathrm{Se}_{\mathrm{x}}$ flake prepared via the FIB technique. 

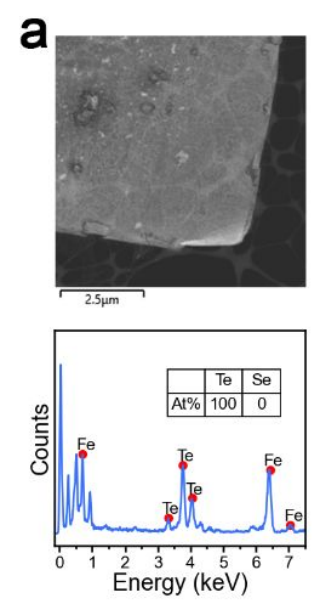
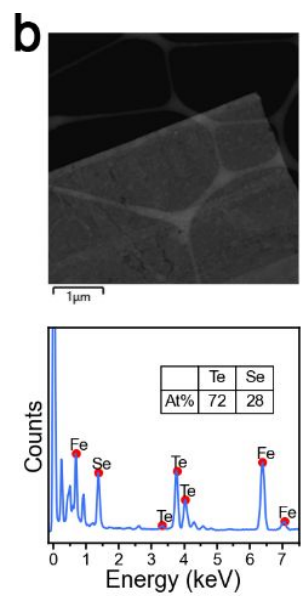
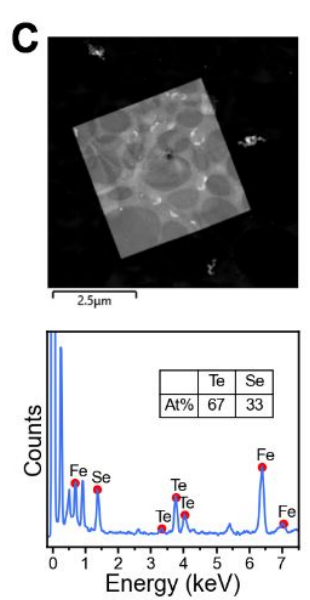
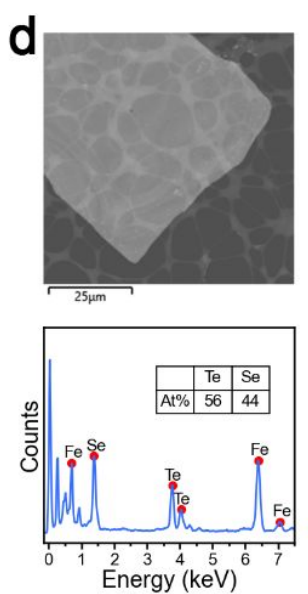
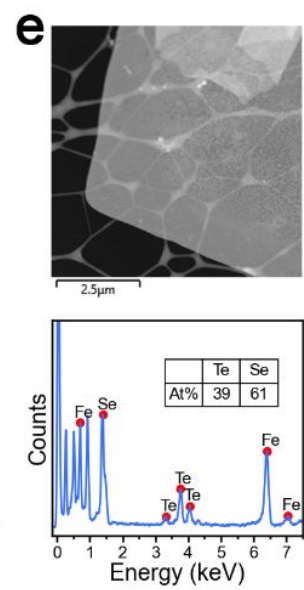

Figure S8. (a-e) STEM images and the corresponding EDS spectra of $\mathrm{FeTe}_{1-\mathrm{x}} \mathrm{Se}_{\mathrm{x}}$ with different compositions. Specifically, (a) $x=0$, (b) 0.28, (c) 0.33, (d) 0.44, and (e) 0.61. 

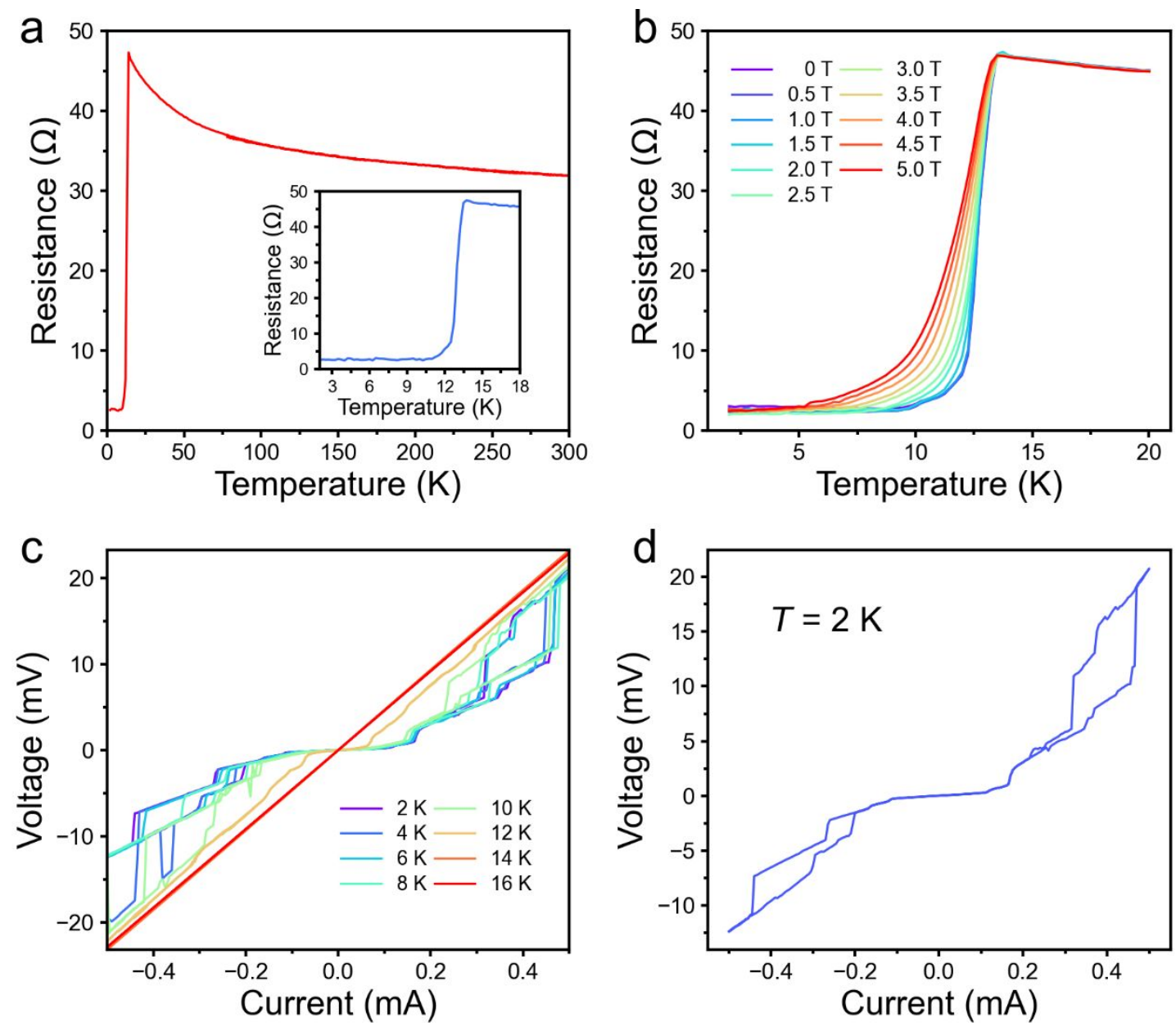

Figure S9. Low-temperature transport measurement of the $\mathrm{FeTe}_{1-\mathrm{x}} \mathrm{Se}_{\mathrm{x}}$ sample prepared by using $\mathrm{FeCl}_{2}$ as the iron precursor. (a) Temperature-dependence of the longitudinal resistance. The inset is the magnified plot from $2 \mathrm{~K}$ to $18 \mathrm{~K}$. (b) Temperature-dependent resistance measured under different magnetic fields. (c) Current-voltage curves at different temperatures. (d) Current-voltage curve measured by sweeping the current at $2 \mathrm{~K}$. 


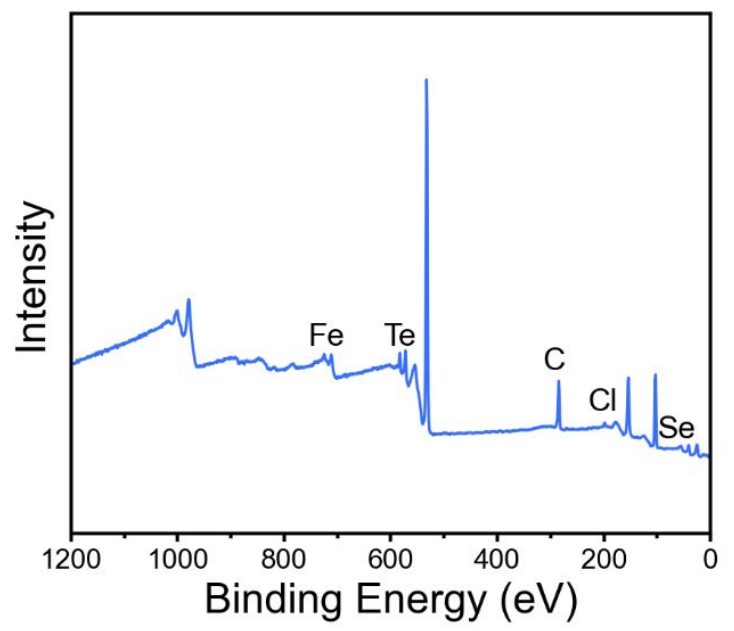

Figure S10. XPS survey spectra of $\mathrm{FeTe}_{1-\mathrm{x}} \mathrm{Se}_{\mathrm{x}}$ prepared by using $\mathrm{FeCl}_{2}$ as the iron precursors. 

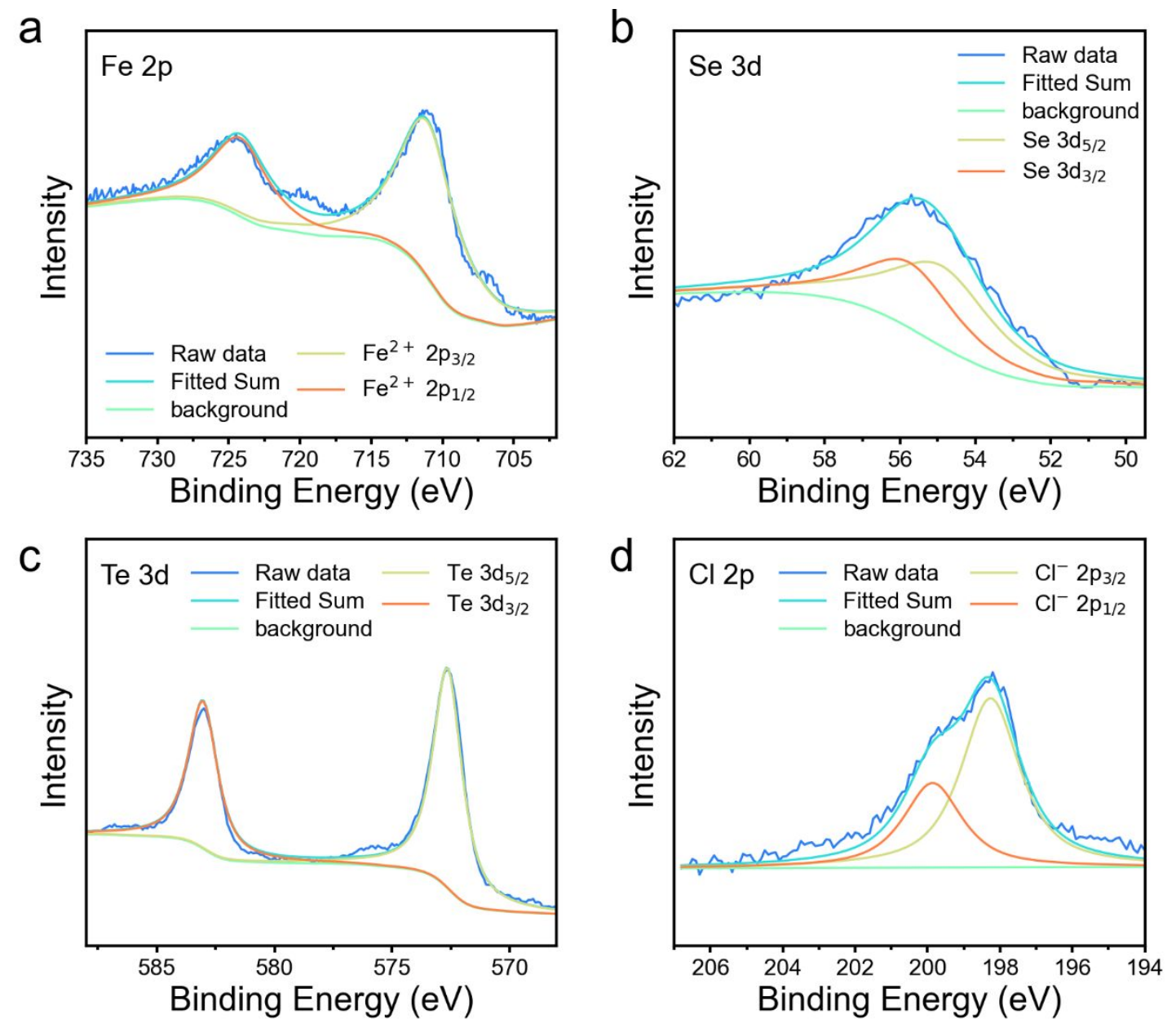

Figure S11. High-resolution XPS spectra of $\mathrm{FeTe}_{1-\mathrm{x}} \mathrm{Se}_{\mathrm{x}}$ nanosheets prepared by using $\mathrm{FeCl}_{2}$ as the iron precursor, including (a) Fe 2p; (b) Se 3d; (c) Te 3d; (d) Cl 2p. 

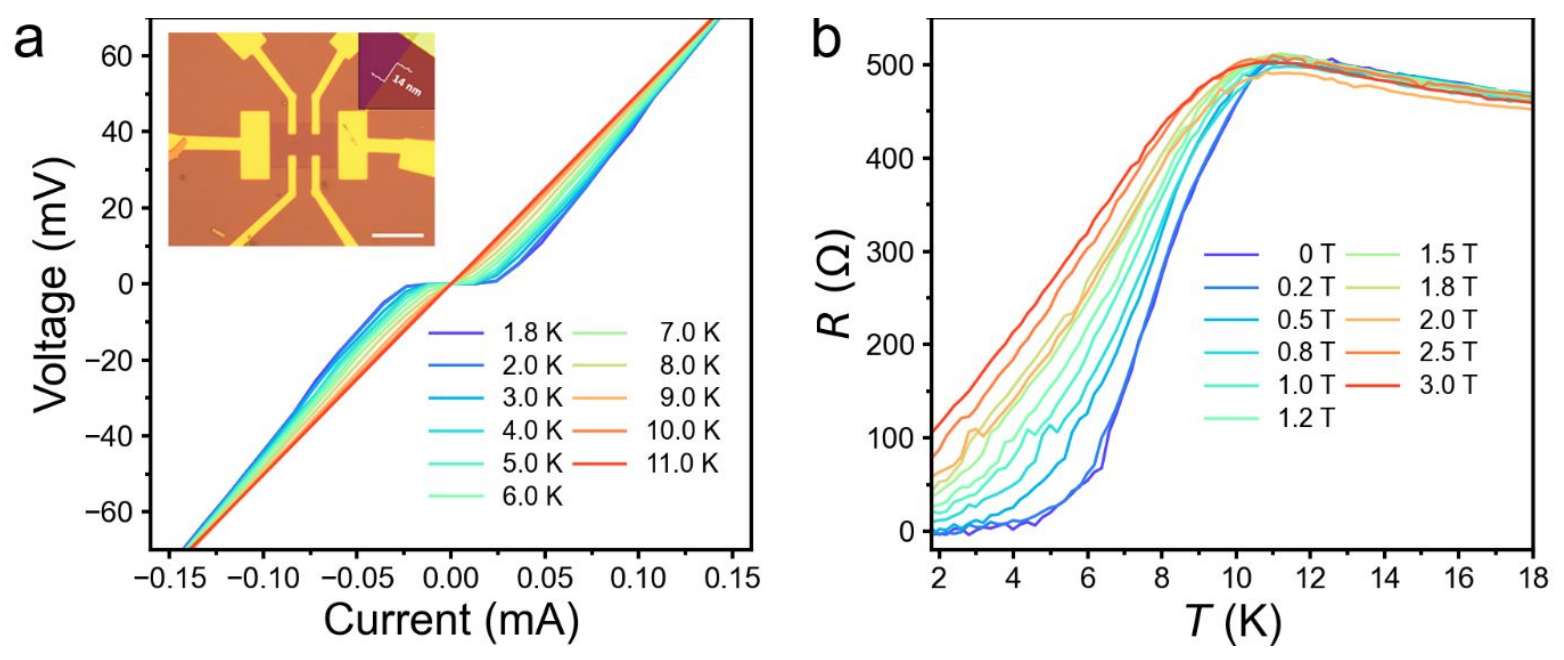

Figure S12. Low-temperature transport measurement of a 14-nm $\mathrm{FeTe}_{1-\mathrm{x}} \mathrm{Se}_{\mathrm{x}}$ sample. (a) Current-voltage curves at different temperatures. The inset is the optical image of the device and the corresponding AFM result, scale bar: $20 \mu \mathrm{m}$. (b) Temperature-dependent resistance measured under different magnetic fields. 


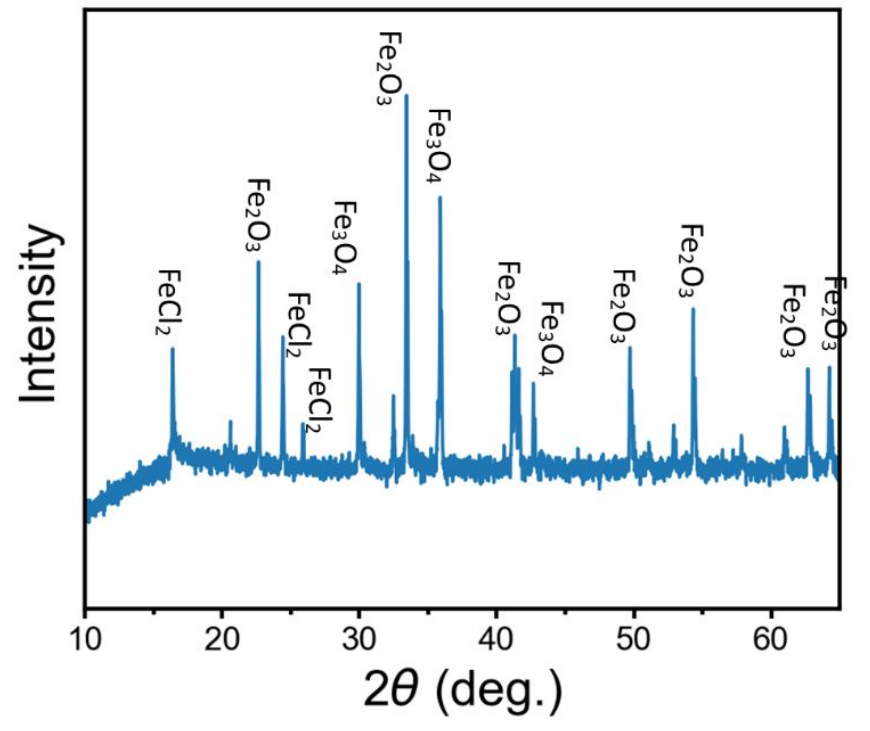

Figure S13. XRD pattern of $\mathrm{Fe}_{2} \mathrm{O}_{3} / \mathrm{FeCl}_{2}$ precursor after the reaction without adding chalcogenide precursor at the upstream. 


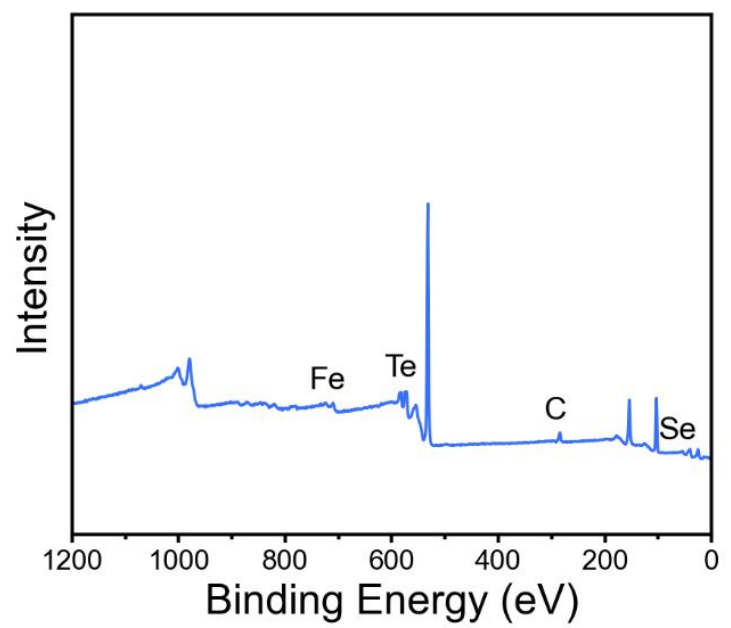

Figure S14. XPS survey spectrum of $\mathrm{FeTe}_{1-\mathrm{x}} \mathrm{Se}_{\mathrm{x}}$ prepared by using $\mathrm{Fe}_{2} \mathrm{O}_{3} / \mathrm{FeCl}_{2}$ as the iron precursor. 

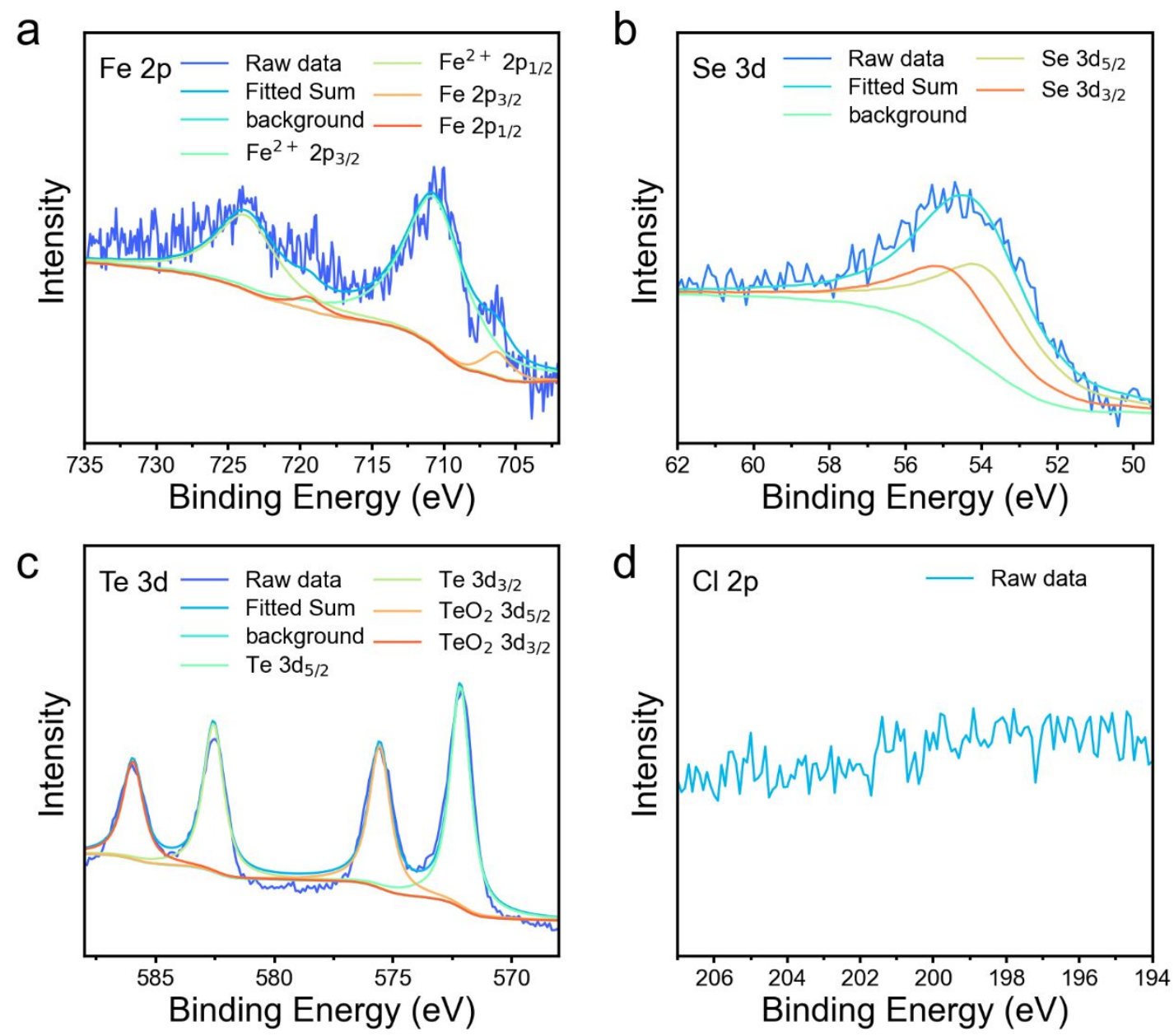

Figure S15. High-resolution XPS spectra of $\mathrm{FeTe}_{1-\mathrm{x}} \mathrm{Se}_{\mathrm{x}}$ nanosheets prepared by using $\mathrm{Fe}_{2} \mathrm{O}_{3} / \mathrm{FeCl}_{2}$ as the iron precursor, including (a) Fe 2p; (b) Se 3d; (c) Te 3d; (d) $\mathrm{Cl} 2 \mathrm{p}$. 
Table S1. Lattice constant and lattice mismatch for the $\mathrm{FeTe}_{0.5} \mathrm{Se}_{0.5}$ on different substrates.

\begin{tabular}{|c|c|c|c|c|}
\hline & FeTe $_{\mathbf{0 . 5}} \mathbf{S e}_{\mathbf{0 . 5}}\left(\mathbf{d}_{\mathbf{1 0 0}}\right)$ & $\operatorname{Si}\left(\mathbf{d}_{\mathbf{1 0 0}}\right)$ & $\mathbf{S T O}\left(\mathbf{d}_{\mathbf{1 0 0}}\right)$ & $\mathbf{S T O}\left(\mathbf{d}_{\mathbf{1 1 0}}\right)$ \\
\hline $\begin{array}{c}\text { Lattice } \\
\text { constant }\end{array}$ & $0.3796 \mathrm{~nm}$ & $0.5431 \mathrm{~nm}$ & $0.3910 \mathrm{~nm}$ & $0.2765 \mathrm{~nm}$ \\
\hline $\begin{array}{c}\text { Lattice } \\
\text { mismatch for } \\
\text { FeTe }_{\mathbf{0 . 5}} \text { Se }_{0.5}\end{array}$ & ---- & $43 \%$ & $3 \%$ & $-27 \%$ \\
\hline
\end{tabular}

Despite the large lattice mismatch between $\mathrm{FeTe}_{0.5} \mathrm{Se}_{0.5}$ and $\mathrm{Si}$, we can still obtain sample with large size and good quality on the substrate, which is also the advantage of our CVD method. 


\section{Note S1. Discussion about the upper critical field}

The upper critical field, $B_{c 2}(T)$, can be understood through the conventional WerthamerHelfand-Hohenberg (WHH) model or the Ginzburg-Landau (GL) model. In the WHH model, the upper critical field includes orbital and Pauli limitations, which can be extrapolated as $B_{c 2}$ $(0)=-0.693\left(\frac{d B_{c 2}}{d T}\right)_{T_{c}} T_{c} \cdot{ }^{1,2}$ Taking $\left(\frac{d B_{c 2}}{d T}\right)_{T_{c}}=-3.83 \mathrm{~T} / \mathrm{K}$ from Figure $4 \mathrm{f}$ in the main text, we obtain $\mathrm{B}_{\mathrm{c} 2}(0)=31.6 \mathrm{~T}$ using the WHH model. Consequently, we evaluate the orbital-limited upper critical field $B_{c 2}^{o r b}=38.45 \mathrm{~T}$ using $B_{c 2}^{o r b}=\sqrt{1+\alpha^{2}} B_{c 2}(0)$, where $\alpha$ is the Maki parameter $\left(\alpha=0.693\right.$ in this scenario). Applying $B_{c 2}^{o r b}=\frac{\phi_{0}}{2 \pi \xi^{2}}, 3,4$ the coherence length $\xi(0)=2.93 \mathrm{~nm}$ at 0 K. For the GL model, we obtain $B_{c 2}(T)=B_{c 2}(0)\left(1-\frac{2 T^{2}}{T^{2}+T_{c}^{2}}\right) \cdot{ }^{5}$ Figure S16 shows that the temperature dependence of $B_{c 2}(T)$ is well-fitted with the GL model. We derive the $T_{c}=11.93$ $\mathrm{K}$, in agreement with our experimental data. The corresponding $\mathrm{B}_{\mathrm{c} 2}(0)$ is $41.5 \mathrm{~T}$ with a coherence length $\xi(0)=2.81 \mathrm{~nm}$ at $0 \mathrm{~K}$, based on formula $B_{c 2}=\frac{\phi_{0}}{2 \pi \xi_{G L}^{2}}\left(1-\frac{T}{T_{c}}\right) \cdot 6,7$ We realize that a narrow temperature range of the experimental data of $B_{c 2}(T)$ due to the measurement limitation might induce a fitting error to the evaluation of critical parameters. Therefore, we did not draw the fitting curve of temperature-dependent $B_{c 2}(T)$ in the main text. The abovementioned parameters based on two different models are concluded in Table S2. 


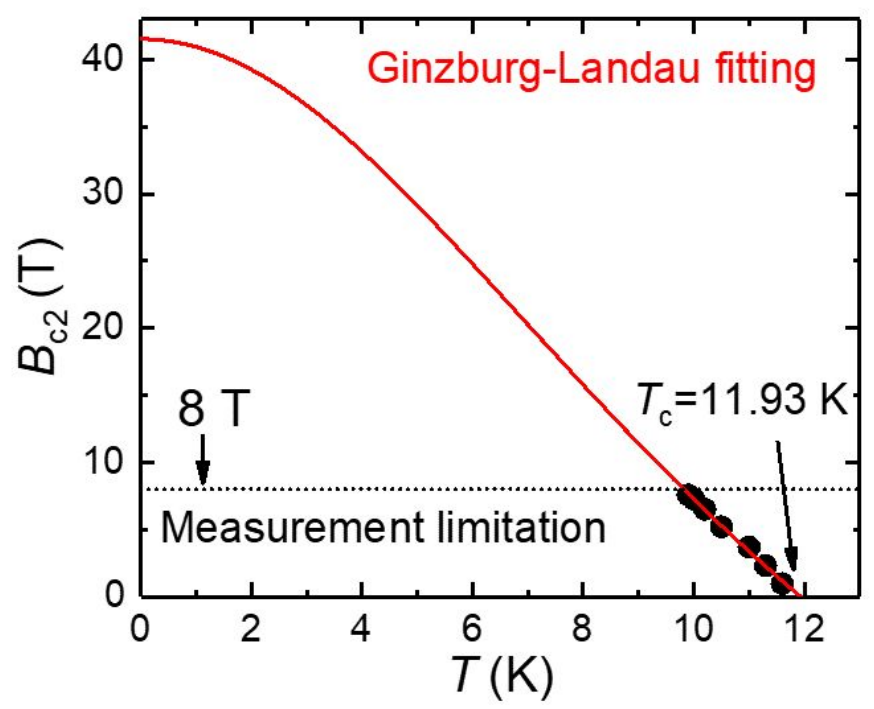

Figure S16. Temperature dependence of the upper critical field. The black dots denote the experimental data, and the red line denotes the Ginzburg-Landau fitting curve.

Table S2. Critical parameters based on the WHH model and the GL model.

\begin{tabular}{|c|c|c|c|c|}
\hline Model & $T_{\mathrm{C}}$ & $B_{\mathrm{C}_{2}}(\mathbf{0})$ & $\left(\frac{d B_{c 2}}{d T}\right)_{T c}$ & $\xi(0)$ \\
\hline WHH & \multirow{2}{*}{$11.9 \mathrm{~K}$} & $31.6 \mathrm{~T}$ & $-3.83 \mathrm{~T} / \mathrm{K}$ & $2.93 \mathrm{~nm}$ \\
\hline GL & & $41.5 \mathrm{~T}$ & - & $2.81 \mathrm{~nm}$ \\
\hline
\end{tabular}




\section{Note S2. Discussion about the thickness control and the choice of iron precursor}

We control the thickness in a kinetic way. Since decreasing the reaction temperature will decrease both the vapor pressure of reactant $\left(\mathrm{FeCl}_{2}\right)$ and reaction rate simultaneously, it is not surprising that thinner $\mathrm{FeTe}_{1-\mathrm{x}} \mathrm{Se}_{\mathrm{x}}$ nanosheets can be obtained at the lower reaction temperature. In addition to the reaction temperature, it is noteworthy to mention that the choice of a suitable iron precursor is very important to get uniform products. ${ }^{8,9}$ In our protocol, a mixture of $\mathrm{Fe}_{2} \mathrm{O}_{3}$ and $\mathrm{FeCl}_{2}$ powders were used as the iron precursor, in which $\mathrm{FeCl}_{2}$ with higher chemical reactivity is the reactant for producing $\mathrm{FeTe}_{1-\mathrm{x}} \mathrm{Se}_{\mathrm{x}}$, while $\mathrm{Fe}_{2} \mathrm{O}_{3}$ acts as an additive to control the release of $\mathrm{FeCl}_{2}$ vapor and thus the reaction rate. $\mathrm{Fe}_{2} \mathrm{O}_{3}$ could bring in two effects. First, the melting points of $\mathrm{Fe}_{2} \mathrm{O}_{3}$ and its reduction product $\mathrm{Fe}_{3} \mathrm{O}_{4}$ are very high $\left(1565^{\circ} \mathrm{C}\right.$ for $\mathrm{Fe}_{2} \mathrm{O}_{3}$ and $1597{ }^{\circ} \mathrm{C}$ for $\mathrm{Fe}_{3} \mathrm{O}_{4}$ ). Thus, the oxide precursor is not able to supply enough vapor pressure for the growth of $\mathrm{FeTe}_{1-\mathrm{x}} \mathrm{Se}_{\mathrm{x}}$ at our reaction temperatures $\left(500-550{ }^{\circ} \mathrm{C}\right)$. Instead, $\mathrm{Fe}_{2} \mathrm{O}_{3}$ can act as a physical filter for releasing the $\mathrm{FeCl}_{2}$ vapor, which ensures its stable release, thus providing more controllable reactant $\left(\mathrm{FeCl}_{2}\right)$ concentration in the gas phase. The inhibitor effect of the inert oxides was well studied in another work in the case of preparing Mo-based transition metal dichalcogenide (TMD) materials by the CVD method. ${ }^{10}$ Second, metal chlorides typically have high chemical reactivity. In our case, the reduction of $\mathrm{Fe}_{2} \mathrm{O}_{3}$ in $\mathrm{Ar} / \mathrm{H}_{2}$ atmosphere will in situ generate $\mathrm{Fe}_{3} \mathrm{O}_{4}$ and $\mathrm{H}_{2} \mathrm{O}$ vapor $\left(\mathrm{Fe}_{2} \mathrm{O}_{3}+\mathrm{H}_{2} \rightarrow \mathrm{Fe}_{3} \mathrm{O}_{4}+\mathrm{H}_{2} \mathrm{O}\right)$, which can be confirmed by the XRD pattern (Figure S13). The in situ generated $\mathrm{H}_{2} \mathrm{O}$ vapor could further react with $\mathrm{FeCl}_{2}\left(\mathrm{FeCl}_{2}+\mathrm{H}_{2} \mathrm{O} \rightarrow \mathrm{Fe}(\mathrm{OH}) \mathrm{Cl}+\mathrm{HCl}\right),{ }^{11}$ which can help to deplete the $\mathrm{Cl}^{-}$ions (the absence of $\mathrm{Cl}$ element is demonstrated in the XPS spectra in Figure S14 and S15) and is likely to slow down the reaction. In summary, both the choice of a suitable precursor and the control over reaction temperature are important to obtain $\mathrm{FeTe}_{1-\mathrm{x}} \mathrm{Se}_{\mathrm{x}}$ nanosheets with 
controllable and uniform thickness. Besides, we observed better low temperature transport property by choosing $\mathrm{Fe}_{2} \mathrm{O}_{3} / \mathrm{FeCl}_{2}$ as the iron precursor, and it could be ascribed to the decreased amount of the $\mathrm{Cl}^{-}$dopant in the sample. In addition, it was reported that oxygen annealing could enhance the bulk superconductivity of the $\mathrm{FeTe}_{1-\mathrm{x}} \mathrm{Se}_{\mathrm{x}}$ crystal. ${ }^{12-14}$ Since there is an obvious oxidized Te peak in the XPS spectrum (Figure S15), the in situ generated water vapor might have a similar effect.

\section{References}

(1) Snider, E.; Dasenbrock-Gammon, N.; McBride, R.; Debessai, M.; Vindana, H.; Vencatasamy, K.; Lawler, K. V.; Salamat, A.; Dias, R. P. Room-temperature superconductivity in a carbonaceous sulfur hydride. Nature 2020, 586 (7829), 373-377.

(2) Werthamer, N. R.; Helfand, E.; Hohenberg, P. C. Temperature and purity dependence of the superconducting critical field, $H_{\mathrm{c} 2}$. III. Electron spin and spin-orbit effects. Phys. Rev. 1966, 147 (1), 295-302.

(3) Glezer Moshe, A.; Farber, E.; Deutscher, G. From orbital to Pauli-limited critical fields in granular aluminum films. Phys. Rev. Research 2020, 2 (4), 043354.

(4) Mozaffari, S.; Sun, D.; Minkov, V. S.; Drozdov, A. P.; Knyazev, D.; Betts, J. B.; Einaga, M.; Shimizu, K.; Eremets, M. I.; Balicas, L.; Balakirev, F. F. Superconducting phase diagram of $\mathrm{H}_{3} \mathrm{~S}$ under high magnetic fields. Nat. Commun. 2019, 10 (1), 2522. 
(5) Carbotte, J. P. Properties of boson-exchange superconductors. Rev. Mod. Phys. 1990, $62(4), 1027-1157$.

(6) Xi, X.; Wang, Z.; Zhao, W.; Park, J.-H.; Law, K. T.; Berger, H.; Forró, L.; Shan, J.; Mak, K. F. Ising pairing in superconducting $\mathrm{NbSe}_{2}$ atomic layers. Nat. Phys. 2016, 12 (2), 139143.

(7) Tsen, A. W.; Hunt, B.; Kim, Y. D.; Yuan, Z. J.; Jia, S.; Cava, R. J.; Hone, J.; Kim, P.; Dean, C. R.; Pasupathy, A. N. Nature of the quantum metal in a two-dimensional crystalline superconductor. Nat. Phys. 2016, 12 (3), 208-212.

(8) Cui, F.; Zhao, X.; Xu, J.; Tang, B.; Shang, Q.; Shi, J.; Huan, Y.; Liao, J.; Chen, Q.; Hou, Y.; Zhang, Q.; Pennycook, S. J.; Zhang, Y. Controlled growth and thickness-dependent conduction-type transition of $2 \mathrm{D}$ ferrimagnetic $\mathrm{Cr}_{2} \mathrm{~S}_{3}$ semiconductors. Adv. Mater. 2020, 32 (4), 1905896.

(9) Zheng, J.; Yan, X.; Lu, Z.; Qiu, H.; Xu, G.; Zhou, X.; Wang, P.; Pan, X.; Liu, K.; Jiao, L. High-mobility multilayered $\mathrm{MoS}_{2}$ flakes with low contact resistance grown by chemical vapor deposition. Adv. Mater. 2017, 29 (13), 1604540.

(10) Shi, R.; He, P.; Cai, X.; Zhang, Z.; Wang, W.; Wang, J.; Feng, X.; Wu, Z.; Amini, A.; Wang, N.; Cheng, C. Oxide Inhibitor-assisted growth of single-layer molybdenum dichalcogenides $\left(\mathrm{MoX}_{2}, \mathrm{X}=\mathrm{S}, \mathrm{Se}, \mathrm{Te}\right)$ with controllable molybdenum release. ACS Nano 2020, $14(6), 7593-7601$.

(11) Schröder, D.; Schwarz, H. Thermochemistry of neutral and cationic iron hydroxides $\mathrm{Fe}(\mathrm{OH})_{\mathrm{n}}{ }^{0 /+}(\mathrm{n}=1,2)$ in the gas phase. Int. J. Mass Spectrom. 2003, 227 (1), 121-134. 
(12) Sun, Y.; Tsuchiya, Y.; Taen, T.; Yamada, T.; Pyon, S.; Sugimoto, A.; Ekino, T.; Shi, Z.; Tamegai, T. Dynamics and mechanism of oxygen annealing in $\mathrm{Fe}_{1+\mathrm{y}} \mathrm{Te}_{0.6} \mathrm{Se}_{0.4}$ single crystal. Sci. Rep. 2014, 4, 4585-4585.

(13) Kawasaki, Y.; Deguchi, K.; Demura, S.; Watanabe, T.; Okazaki, H.; Ozaki, T.; Yamaguchi, T.; Takeya, H.; Takano, Y. Phase diagram and oxygen annealing effect of $\mathrm{FeTe}_{1-\mathrm{x}} \mathrm{Se}_{\mathrm{x}}$ iron-based superconductor. Solid State Commun. 2012, 152 (13), 1135-1138.

(14) Zhao, P. H.; Zhu, H. F.; Tian, Y. J.; Li, D. L.; Ma, L.; Suo, H. L.; Nie, J. C. O2 Annealing induced superconductivity in $\mathrm{FeTe}_{1-\mathrm{x}} \mathrm{Se}_{\mathrm{x}}$ : on the origin of superconductivity in FeTe films. $J$. Supercond. Nov. Magn. 2017, 30 (4), 871-876. 